\title{
Identidades e representações do urbano na imprensa: um estudo sobre a "cidade da Oktoberfest" no Vale do Paranhana (RS, Brasil)
}

\author{
Elisete de Souza Ramão $\mathrm{Paz}^{\star}$
}

Daniel Luciano Gevehr**

\author{
Palavras-chave: \\ Representações Sociais \\ Identidade \\ Imaginários Urbanos
}

Keywords:

Social representations

Identity

Urban imaginary

\begin{abstract}
Resumo: O estudo analisa as imagens construídas sobre o município de Igrejinha/RS, nas publicações do seu principal jornal local, no período de 2014 - momento em que o município completa seu $50^{\circ}$ aniversário de emancipação. Buscou-se compreender os recursos utilizados pela imprensa para produzir e difundir determinadas imagens sobre Igrejinha, que tiveram como objetivo difundir representações sobre o município, diretamente associadas às comemorações da Oktoberfest. Nessa perspectiva, constatou-se que existe um olhar positivo sobre a cidade, a partir das publicações do seu principal veículo de comunicação, uma vez que, em sua maioria, as notícias exaltam seu potencial cultural, turístico, industrial e empresarial, procurando, com isso, contribuir para o desenvolvimento local e regional.
\end{abstract}

\begin{abstract}
The study analyzes the images constructed on the city of Igrejinha (RS), in the publications of its main local newspaper, for the period 2014 - when the city celebrates its 50th anniversary of emancipation. He sought to understand the resources used by the press to produce and disseminate certain images on Igrejinha, which aimed to disseminate representations of the city, directly associated with the celebration of Oktoberfest. In this perspective, it was found that there is a positive view of the city, from the publications of its main means of communication, since, in most cases, the news extolling its cultural potential, tourism, industrial and business, looking with so contribute to local and regional development.
\end{abstract}

Recebido em 17 de outubro de 2016. Aprovado em 21 de agosto de 2017.

\section{Introdução}

A pesquisa realiza uma investigação sobre o processo de construção da identidade cultural do município de Igrejinha, um município de aproximadamente 33 mil habitantes (2010), que faz parte do Vale do Paranhana, região localizada no Nordeste do Rio Grande do Sul. Através das representações construídas e difundidas sobre o espaço urbano de Igrejinha pretendemos compreender o processo de produção de parte dos seus imaginários urbanos, que são manipulados através da imprensa local.

Para trabalhar com esse tipo de fonte - a imprensa - a presente pesquisa fez uso de uma metodologia capaz de organizar o material para análise, uma vez que o jornal local apresenta variedade de temas em suas publicações. Devido a isso, valemo-nos da metodologia de análise de conteúdo, e, na categorização, através do qual se fizeram recortes do texto em unidades de análises temáticas do conteúdo. Após a divisão das unidades, procedemos a descrição e a interpretação desse conteúdo.

Percebe-se, ao longo do tempo, que os municípios do Vale do Paranhana - entre eles Igrejinha - foram se modificando, se redefinindo e produzindo uma imagem perante seu público - habitantes, visitantes e regiões vizinhas. Esse processo acabou contribuindo de forma decisiva para a criação da imagem de Igrejinha como " $A$ Cidade do Calçado e da Oktoberfest", epígrafe que aparece nos pórticos de entrada do município, e em inúmeras publicações de veículos de comunicação,

\footnotetext{
* Mestre em Desenvolvimento Regional pelas Faculdades Integradas de Taquara (FACCAT). Possui graduação em Comunicação Social - Habilitação Relações Públicas - (FACCAT) e especialização em Comunicação Corporativa - Faculdade Integrada da Grande Fortaleza (FGF). E-mail: contato. elisetepaz@gmail.com.

** Doutor em História. Possuí graduação e mestrado em História. É professor do Programa de Pós-Graduação em Desenvolvimento Regional das Faculdades Integradas de Taquara (FACCAT). E-mail: danielgevehr@hotmail.com.
} 
como mídia impressa e eletrônica, nas últimas décadas.

Aspectos culturais ligados à etnicidade também são importantes, nessa pesquisa, que estuda a cidade a partir da sua relação com a "germanidade", apresentando-se este aspecto como uma questão a ser investigada e procurando compreender como se emprega a festa da Oktoberfest como uma representação cultural das comunidades de origem germânica na região nordeste do Rio Grande do Sul.

Atentamos para os sistemas classificatórios de produção de identidades, que nos faz pensar na afirmação da germanidade - como uma categoria que remete à identidade étnica compartilhada e que os faz "lembrar e perpetuar" o passado da Imigração Alemã. Com isso, citamos o estudo de Seyferth (2011) que nos mostra o papel desempenhado pelo Deutschtum, que para ela expressa a germanidade, ou seja, o jeito de ser alemão no Brasil e que une os imigrantes e seus descendentes através da etnicidade.

Em um momento seguinte, são discutidas as conceituações acerca dos temas da identidade cultural, da memória, da etnicidade, do espaço e da localidade, das representações sociais e dos imaginários urbanos. A seção seguinte estuda de forma mais aprofundada as memórias sociais do município de Igrejinha, no que se refere à região e suas características, bem como a origem do nome, a vinda dos primeiros imigrantes, as origens da Oktoberfest (mundial), e a criação da Oktoberfest de Igrejinha. Finalmente, aprofunda-se a análise das publicações veiculadas pela imprensa local, que em nosso entendimento, tiveram o propósito de difundir uma imagem sobre a cidade repercutida nessas edições do seu jornal.

\section{Identidades e representações: a construção da imagem da cidade na imprensa}

Iniciamos a discussão com a teoria proposta por Hall (2006), que compreende a identidade cultural como uma construção dos sujeitos que se dá através dos processos sociais. $\mathrm{O}$ autor explica que, se fosse inata, a identidade cultural não precisaria ser evocada, evidenciada e narrada. Segundo ele, a luta pela afirmação identitária emerge sempre que há alguma dúvida ou incerteza, e esse esforço por evidenciar determinada identidade cultural pode ser percebido em diferentes tempos e lugares, na medida em que as pessoas buscam pelos referenciais históricos que sustentem o discurso que pretendem afirmar.

Uma importante contribuição é trazida por Candau (2012), que trata das identidades, seja de uma pessoa, ou de comunidades, em que ele as associa diretamente com suas memórias. Em seus estudos, encontram-se concepções simplificadas a respeito de identidade e memória, mas que ele afirma se tratarem de um consenso entre os pesquisadores: o reconhecimento da identidade como uma "construção social" e da memória como uma "reconstrução continuamente atualizada do passado".

Para compreensão da noção de etnicidade, nos valemos da ideia de que a etnicidade está diretamente relacionada aos "[...] fenômenos sociais que refletem as tendências positivas de identificação e inclusão de certos indivíduos em um grupo étnico" (GRÜNEWALD, 2003, p. 145). Para tanto, deve-se considerar a distintividade dessa identidade, uma vez que para caracterizar um grupo étnico, deve se observar a noções de origem, de história, de cultura e, até mesmo, de raça comum.

Já sobre a ideia de espaço - que se relaciona diretamente com a problemática que pretendemos estudar - podemos entender que "[...] o valor de um dado elemento do espaço [...] é dado pelo conjunto da sociedade, e se exprime através da realidade do espaço em que se encaixou" (SANTOS, 2006, p. 26). Nesse contexto, o conceito de espaço relaciona-se com os diferentes conceitos entre lugar, paisagem, território e região, podendo ser um ou todos, mas de forma distinta, e em um misto entre material e humano (SANTOS, 2006).

Observa-se, ainda, a presença marcante das origens na memória social migrante que usa de elementos e símbolos para facilitar a construção de uma identidade de grupo, acentuando a permanência da origem, tais quais como: cozinha, indumentária, expressões e perfis corporais, gestualidade, ritos 
religiosos (CANDAU, 2012). O autor afirma que não é um território de um só lugar que constitui o grupo, "mas uma memória ligada a uma sucessão de lugares de uso e habitação" (CANDAU, 2012, p. 158), como se pode observar a respeito de lugares de memória de grupos e imigrantes, que é o caso que está sendo analisado neste artigo. Para o autor, os lugares "atravessam a memória viva”, são duráveis e carregados de história e memória.

Ampliando a discussão sobre o campo das significações e das representações sociais, pode-se citar as pesquisas realizadas por Pesavento (1995), que associa a representação a uma relação ambígua entre ausência e presença. A autora argumenta que vê a representação como uma "[...] presentificação de um ausente, que é dado a ver segundo uma imagem, mental ou material, que se distancia do mimetismo puro e simples e trabalha com uma atribuição de sentido [...]". (PESAVENTO, 1995, p. 280).

Também Chartier (2002) discute sobre o duplo sentido da representação, afirmando que essa tem uma dupla função, que seria "tornar presente uma ausência". O autor vê a imagem como "a instrumentalização da força, o meio da potência, e sua fundação em poder". Seguindo nessa ideia, o autor menciona a representação como imagem que remete à ideia e à memória os objetos ausentes. Segundo ele, esses objetos ausentes podem ser coisas, conceitos, pessoas. Nesse sentido, a representação mostra o objeto ausente, substituindo-o por uma imagem capaz de representá-lo adequadamente. Representar é fazer conhecer pelas palavras e gestos, por exemplo, assim como poderia ser por uma pintura, figuras, marcas.

Pode-se também citar os textos como forma de representação, uma vez que eles podem, de diversas maneiras, reconhecer e experimentar os poderes das imagens. Assim, é possível compreender o quanto a comunicação escrita, os textos, os artigos, as matérias jornalísticas e outros elementos textuais podem ter êxito no sentido de produzir representações e imaginários na mente de seus leitores.

Spink (1993), por sua vez, acredita que apenas alguns indivíduos, grupos ou setores da sociedade se constituem em protagonistas desse processo. Os demais, que formam, de fato, a maioria, apenas consomem conteúdos (normas, valores etc.) que não produziram. Ou seja, é nesse contexto que surge a força da mídia que, segundo a autora, em suas diferentes facetas, tem protagonizado de modo crescente essa função pragmática de "explicar o mundo" e produzir significado para fatos e acontecimentos sob a forma de representações sociais.

Corroborando com a linha de raciocínio de Spink (1993), encontram-se os estudos de Leitão e Santos (2012), que pesquisaram sobre a imagem jornalística e as representações sociais. Estes autores consideram importante, dentro desse contexto, o conceito de agenda-setting, uma vez que, segundo eles, o público dá importância a acontecimentos enfatizados pelos meios de comunicação de massa. Spink explica que a mídia coloca na ordem do dia os assuntos, dando ênfase e centralidade ao que se quiser e ao que for interessante a um grupo de pessoas etc.

Esse pensamento está de acordo com a afirmação de Hall (1997, p. 184), para quem “[...] as mensagens enunciadas por um jornal inseremse - ou lutam por se inserir - no imaginário social presente em determinada época”. O autor explica que tais mensagens expressam pressupostos que pertencem ao estoque cultural das sociedades nas quais eles operam, e que as ideologias em fotos e textos de um jornal não produzem novos saberes sobre o mundo, mas produzem um reconhecimento do mundo (HALL, 1997).

Bourdieu (2002) problematiza ainda sobre o poder da convicção, e sua relação com a sinceridade, ou credibilidade, apontando a necessidade de um "acordo perfeito e imediato" entre as expectativas inscritas na posição ocupada e as disposições do ocupante. $\mathrm{O}$ autor discute sobre um "ajustamento das disposições às posições", usando como exemplo o ajustamento de um jornal ao seu público, ou seja, explicando que as estruturas de objetivas do campo da produção estão na origem das categorias de percepção e apreciação dos produtos. Em outras palavras, pode-se entender que existe uma relação de estreitamento - e talvez até de dependência - entre o que é produzido com o 
que é apreciado e, consequentemente, consumido. Levando novamente para o contexto da imprensa, percebemos que o que é publicado em um jornal local, é fruto do que se espera ler, é resultado de uma apreciação já demonstrada, de seu público leitor. E é por isso que, em sua repercussão, determinada matéria pode demonstrar tanta credibilidade e aceitação.

Bourdieu (2002) também destaca outro ponto, que é a força de um "agente singular", que fala e age em nome de um grupo, como porta-voz do discurso. Segundo ele, a eficácia simbólica do discurso de autoridade depende sempre, em certa medida, da competência linguística daquele que o emprega.

Tendo estas categorias como ponto de partida de nosso estudo, nos aproximamos da noção de "cidade", que traduz a ideia de espacialidade, fazendo-nos pensar nas singularidades presentes no espaço urbano de Igrejinha (RS). Pode-se afirmar que as cidades são exemplos, entre outras coisas, de projeção dos imaginários sociais no espaço. Segundo Baczko (1985, p. 313), “[...] a sua organização espacial atribui um lugar privilegiado ao poder, explorando a carga simbólica das formas (o centro opõe-se a periferia, o "acima" opõe-se ao "abaixo" etc.)" relacionamos esta noção, com as contribuições trazidas por Neves (2004) e Abreu (1998), que afirmam que as relações entre o passado e a questão da memória, são fundamentais para uma análise sobre as cidades e, sobretudo, para a construção de sua imagem.

Para Neves (2004, p. 137), “[...] o caráter coletivo da memória das cidades encontra na literatura terreno fértil de expressão. Como signo da modernidade, são as cidades realidades sempre em mutação". O autor acrescenta ainda que "[...] as relações de poder, atividades econômicas, formas de sociabilidade, vida cultural e espaços coletivos transformam-se de forma contínua" (NEVES, 2004, p. 137). Abreu (1998), por seu turno, explica que a valorização do passado das cidades é uma característica comum às sociedades recentes e que, no Brasil, essa tendência é inédita e reflete uma mudança significativa nos valores e nas atitudes sociais até agora predominantes.

\section{Um pouco da trajetória da cidade: Igrejinha, a imigração alemã a Oktoberfest}

Segundo Engelmann (2004), os primeiros registros de imigrantes no Brasil são de 1820 a 1830, quando as famílias começaram a chegar a terras brasileiras em busca de uma vida nova. Várias pessoas se aventuraram na terra desconhecida, embaladas pela imagem de um sonho que a Coroa Imperial brasileira vendia através de promessas. A chegada às novas terras apresentou aos pioneiros uma realidade muito diferente do que lhes fora prometido. O conjunto de lotes que os imigrantes conquistavam recebia um nome oficial, de origem alemã e, na busca por novas terras, os imigrantes acabaram fixando-se em áreas como o Vale do Paranhana, e, ali, passaram a viver de forma melhor, organizando suas propriedades e fazendo o comércio prosperar.

Devido à construção de uma pequena igreja, que acabou por agrupar uma comunidade, nascia Igrejinha, que passou a ser, inicialmente, uma Vila, o $8^{\circ}$ distrito de Taquara, segundo o Ato Municipal $\mathrm{n}^{\circ} 1$, assinado pelo prefeito da época, Cel. Theobaldo Fleck, em $1^{\circ}$ de janeiro de 1935. Foi somente em $1^{\circ}$ de junho de 1964, que Igrejinha foi emancipada. Percebe-se, até hoje, na cidade de Igrejinha, a influência da colonização germânica, seja nas manifestações culturais, nos costumes ou na arquitetura de vários prédios. Igrejinha, hoje, também é reconhecida pela qualidade da produção de suas indústrias calçadistas.

Os imigrantes também trouxeram a tradição da Oktoberfest para a nova terra, realizando no Brasil festas semelhantes à de Munique (Alemanha), mas de menor porte. A primeira grande Oktoberfest brasileira aconteceu em Blumenau, no estado de Santa Catarina, no ano de 1984. Já a Oktoberfest de Santa Cruz do Sul, no Rio Grande do Sul, surgiu em 1984 também como uma homenagem aos antepassados e à cultura alemã. É considerada a maior do estado; contudo, outros municípios gaúchos também realizam suas festas com participação de grande público, como Cerro Largo e Igrejinha. Idealizada pelo ex-gerente 
da Caixa Econômica Federal, Osvaldo Jungblut, e implantada pelo prefeito da época, Lauri Krause, a Oktoberfest de Igrejinha foi criada no ano de 1988, tendo como referência a festa de Blumenau, com o propósito de resgatar a cultura alemã e promover a integração de seus moradores.

A cada ano, o número de pessoas envolvidas com a festa foi aumentando, com uma comissão voluntária, da comunidade, "puxando" a organização. Nesses 28 anos de Oktoberfest em Igrejinha, é possível citarmos como principais acontecimentos: a indicação de um casal para presidir a festa; a instalação de uma vila alemã, o que representou mais uma ação de preservação da cultura; a criação de uma entidade jurídica para a organização do evento, a Associação de Amigos da Oktoberfest de Igrejinha (AMIFEST); o significativo crescimento da festa devido aos grandes shows; o registro do logotipo da "Oktoberfest de Igrejinha", uma vez que a palavra Oktoberfest é de domínio público; a oficialização da Oktoberfest de Igrejinha como patrimônio cultural do Estado do Rio Grande do Sul; o expressivo aumento do número de atrações/atividades da festa e investimento em shows nacionais.

Kayser (2009) constatou que a imagem de sucesso desse evento se deve a uma combinação de fatores, dentre os quais se destacam dois: a transparência adotada da condução do evento e o comprometimento do voluntariado que, segundo ele, são elementos diferenciais em relação a eventos semelhantes. $\mathrm{O}$ autor ainda menciona a questão da valorização da cultura germânica como um dos principais objetivos da Oktoberfest de Igrejinha.

\section{A Igrejinha dos jornais: entre a identidade e a representação}

O Jornal RS 115, objeto principal de nossa análise, tem sua sede na Rua 25 de Julho, número 180, no centro de Igrejinha. A empresa foi fundada no dia 5 de setembro de 1991, podendo ser considerada experiente no seu ramo de atividade, que trata da produção de um jornal com informações de Igrejinha e sua região. O jornal tem formato de tabloide cinco colunas, com cor na capa e contracapa e sua circulação é semanal. Toda sextafeira, aproximadamente três mil exemplares são distribuídos na cidade sede, Igrejinha, e nas cidades vizinhas de Taquara, Parobé, Três Coroas, Gramado e Canela. O perfil dos leitores é muito variado, já que a linha editorial abrange as seções Política, Geral, Social, Variedades, Esportes, Polícia, entre outros.

Foram analisadas 454 matérias jornalísticas, com a finalidade de se identificar a construção de representações e imaginários sociais nessas notícias da cidade de Igrejinha. As matérias selecionadas foram divididas em quatro grupos temáticos principais: Cultura, Política, Policial e Geral, e cada um desses temas foi subdividido em outras subcategorias. A organização das matérias por temas e categorias possibilitou um maior conhecimento sobre o discurso do jornal, auxiliando a condução da análise. Os números a que se chegou, após a organização, podem ser observados nos quadros a seguir, apresentados a seguir.

Quadro 1 - Matérias Jornal RS115 - 2014 - Grupo CULTURA

\begin{tabular}{cccc}
\hline Oktoberfest & Esportes & Artes/lazer & Memórias \\
\hline 60 & 25 & 16 & 07 \\
\hline \multicolumn{4}{c}{ Total de matérias do grupo Cultura: } \\
\hline
\end{tabular}

Fonte: Elaborado pelos autores.

Tratando-se de um jornal semanal, de poucas páginas, em um universo de 48 edições durante um ano, pode-se afirmar que 108 matérias é um número expressivo de publicações sobre o mesmo assunto: cultura. São, em média, 2,22 matérias por edição, sobre esse tema. Das sete matérias referentes à Memória, quatro são a respeito do aniversário do município que, no ano de 2014, completou 50 anos, e todas remetendo muito à sua etnicidade, ou seja, ao advento da colonização alemã. Isso faz lembrar daquilo que Bourdieu $(1998,2002)$ afirmou, quando referendava a luta que é referida pela definição da identidade regional, também chamada de "identidade étnica", ou seja, uma verdadeira "luta pelas representações", cujo propósito também se pode identificar nas matérias do jornal local de Igrejinha. 
Nesses textos jornalísticos, também podem ser encontrados elementos como a valorização do passado das cidades (ABREU, 1998; CANDAU, 2012), no qual a "germanidade" de Igrejinha é recorrente nas matérias, o que pode ser constatado através de diversos trechos dos textos publicados, em que se busca contar um pouco da história de Igrejinha. Nas publicações, além da referência à colonização alemã, encontram-se termos como "voluntariado", e uma menção à Oktoberfest de Igrejinha como "a maior festa comunitária do Brasil", o que aparece em muitas outras publicações desse jornal, desvelando, assim, alguns dos imaginários urbanos (BACZKO, 1985).

Agrupando as categorias Esportes e Artes/ Lazer, que no total somam-se 41 matérias, pode-se afirmar que, para uma cidade pequena, o número de atletas e pessoas que trabalham, ou possuem algum envolvimento na área do lazer, artes e esportes é relevante, bem como a quantidade de modalidades e atividades esportivas e artísticas oferecidas pelo município, seja através de promoções da Administração Municipal, ou da iniciativa dos próprios grupos, clubes e/ou associações.

Percebe-se que existe um olhar positivo sobre Igrejinha, a partir das publicações pertencentes a essa categoria de análise. Esses acontecimentos, e consequentemente, a publicação de notícias sobre eles, reforçam a ideia de construção de imaginários e de identidade coletiva, bem como de valorização do que é local. Esses elementos servem, em nosso entendimento, para a construção da identidade local.

Como última categoria, e de maior destaque, do grupo Cultura, apresentam-se as matérias sobre a Oktoberfest, que dizem respeito a $56 \%$ do número total, ou seja, mais da metade. Considerando que houve 48 edições no ano todo, constata-se que as publicações referentes à festa não só estiveram presentes em todas as edições do ano como também foram mais que uma matéria por edição. Todos os elementos que fazem referência à Oktoberfest são noticiados, desde a escolha do casal presidente da festa até o repasse da arrecadação. É a partir do senso comum - que circula entre os moradores da cidade - que Igrejinha é conhecida pelo "espírito comunitário", pelo "voluntariado", pelo "povo hospitaleiro" e "trabalhador", por ser uma cidade onde "tudo prospera, cresce e se desenvolve", conforme expressões encontradas nas matérias do jornal e propagadas pelos meios de comunicação local.

Entende-se, a partir disso, que o processo funciona de tal forma que o jornal reforça o imaginárioda população que, por sua vez, impulsiona as publicações do jornal em torno de determinado assunto, servindo-lhe como inspiração. Dessa forma, a população, também inspirada pela mídia que consome, tem sua autoestima alimentada, o que lhe faz querer, cada vez mais, cultivar e imortalizar essa ideia de trabalho, dedicação, desenvolvimento, prosperidade, voluntariado, amor pela tradição, pela cultura alemã, entre outros, fornecendo ainda mais conteúdo para as publicações. É como se tudo estivesse dentro de um círculo, no qual "uma coisa leva a outra", em um mundo de representações (CHARTIER, 1991). Um representa o outro (jornal e população), preenchendo os objetos ausentes e fortalecendo as identidades.

Apresenta-se agora a análise do segundo grupo temático, que trata da Política, com suas categorias: Feitos da Prefeitura, Feitos do Legislativo e Partidos Políticos. Neste grupo, a análise é iniciada com as publicações da categoria Feitos da Prefeitura, sendo esta a pauta de maior destaque. De 454 matérias, no total das 48 edições do ano de 2014, 214 são sobre política, ou seja, $47 \%$ das publicações do jornal. E dessas 214, 171 são sobre os feitos da Prefeitura, o que significa $80 \%$ de tudo o que foi divulgado dentro do grupo Política, e 38\% de tudo o que foi noticiado nesse veículo de comunicação durante o ano de 2014.

Em diversas matérias referentes à categoria Feitos da Prefeitura, nas palavras do prefeito, ou de outros representantes do povo, observam-se alguns signos da imaginação coletiva (BACZKO, 1985), que reforça a identidade coletiva (HALL, 1997) e o poder do discurso (BOURDIEU, 2002), como "amor à terra" e "patriotismo". Observase, também, nas palavras do gestor, a tentativa de construção de um imaginário que remete à ideia de uma boa administração, que cumpre com suas 
promessas e com os compromissos que assume com a comunidade, e também um sutil discurso de crítica em relação à Administração Municipal anterior, que era realizada pelo partido da oposição.

Quadro 2 - Matérias Jornal RS 115 - 2014 - Grupo POLÍTICA

\begin{tabular}{ccc}
\hline Feitos da Prefeitura & $\begin{array}{c}\text { Feitos do } \\
\text { Legislativo }\end{array}$ & Partidos Políticos \\
\hline 171 & 29 & 14 \\
\hline Total de matérias do grupo Política: 214 \\
\hline
\end{tabular}

Fonte: Elaborado pelos autores.

Identificam-se, nessas matérias, as palavras das pessoas que exercem autoridade e passam a ser consideradas como representantes do pensamento oficial de Igrejinha. O estudo sobre os simbolismos presentes nos discursos e, especialmente, sobre $o$ poder e a produção da crença, apresentados pelo sociólogo Bourdieu (2002) são fundamentais para pensar as relações de troca entre a imprensa local, os grupos detentores do poder e o a população que recebe as informações veiculadas pelo jornal.

Vale lembrar neste mesmo contexto, que a teoria proposta por Chartier (1991) afirma que representar também tem um sentido jurídico e político. Representar, segundo ele, é manter o lugar de alguém, ter em mãos a sua autoridade. $\mathrm{E}$ isso também pode ser conferido nas matérias referente à outra categoria do grupo temático: Política.

Já nas matérias referentes à categoria Feitos do Legislativo, a qual apresenta, não somente os trabalhos da Câmara de Vereadores, mas também publicações de grupos de ideologias opostas rivalizando, ataques e defesas, como também, por vezes, se apoiando - nos fazem lembrar o que Baczko (1985) define como um "código coletivo", segundo o qual se exprimem as necessidades e as expectativas, as esperanças e as angústias dos agentes sociais.

Nessa perspectiva, analisa-se a categoria Partido Político, que é a que concentra o menor número de publicações, dentro do grupo temático Política, somando apenas 14 matérias; porém, carregada de simbolismos e de poder de discurso. Iniciamos nossa análise crítica com Baczko (1985), que nos ajuda a pensar sobre o domínio social, que segundo ele, responsabiliza a antropologia política pelo destaque às relações entre sentido e poderio, sistemas simbólicos e estruturas de dominação. É precisamente nesse cenário que estão as matérias sobre os partidos políticos de Igrejinha e por meio das quais se percebem as produções imaginárias, os mitos, os desequilíbrios da sociedade, as tensões no interior das estruturas sociais, as eventuais ameaças de violência, e um conjunto de sistemas simbólicos.

Segue, no Quadro 3, a estrutura do eixo temático Policial e suas categorias Prisões/Crimes e Acidentes/Tragédias. Na coluna policial do jornal são relatadas detenções realizadas no município e na região, bem como ações da Brigada Militar e do Corpo de Bombeiros. Entretanto, em sua maioria, noticiam um caso já solucionado - ladrão preso, acidente atendido pelos bombeiros - construindo, assim, certo imaginário que remete à segurança, uma vez que, segundo o discurso nos textos dessas matérias, deduz-se que a polícia e o corpo de bombeiros têm feito o seu trabalho com eficácia.

Quadro 3 - Matérias Jornal RS 115 - 2014 - Grupo POLICIAL

\begin{tabular}{cc}
\hline Prisões/Crimes & Acidentes/Tragédias \\
\hline 72 & 15 \\
\hline Total de matérias do grupo Política: 87
\end{tabular}

Fonte: Elaborado pelos autores.

Entende-se, assim, no caso das matérias da categoria Prisões/Crimes - as quais representam 83\% das matérias do grupo Policial -, que os imaginários criados na mentalidade dos habitantes de Igrejinha são decorrentes não tanto da notícia sobre os acontecimentos em si - os crimes - mas da forma como são colocados nas manchetes dessas matérias (resolvidos, solucionados), utilizando-se de competências linguísticas, e da relação de forças que dão valor ao discurso. $\mathrm{O}$ mesmo se percebe nas matérias da categoria Acidentes/Tragédias, cujo número de publicações é bem menor, apenas 15 de 87 , mas onde também podem ser encontrados vários signos imaginados.

A seguir, é apresentada a análise das matérias do grupo Geral e suas categorias Releases e Demais 
Notícias (Quadro 4). Aventa-se a possibilidade de que o jornal é composto por cópias de releases (sugestões de pauta) enviados por empresas e instituições da cidade. Em entrevista com a proprietária, foi revelado que não há repórter e que os textos publicados são feitos a partir de notícias enviadas por alguma "fonte".

Quadro 4 - Matérias Jornal RS115 - 2014 - Grupo GERAL

\begin{tabular}{cc}
\hline Releases & Demais Notícias \\
\hline 38 & 07 \\
\hline Total de matérias do grupo Geral: 45
\end{tabular}

Fonte: Elaborado pelos autores.

Nota-se que as matérias não apresentam características de reportagem, ou seja, são superficiais e partidaristas, sempre apresentando apenas um aspecto ou lado da situação, assim como muitos adjetivos positivos, o que caracteriza propaganda nos textos e reforça a dedução de que são publicados exatamente como são recebidos pelo jornal a partir dos envios das assessorias e organizações. Considerando isso, a análise é iniciada com a categoria Releases de Organizações, que significam $84 \%$ das matérias desse grupo temático.

Primeiramente, são apresentadas manchetes de matérias de clubes e associações sem fins lucrativos, envolvidos com atividades sociais. Em diversas matérias, é encontrada a ideia de "solidariedade" e de "responsabilidade social" nos relatos sobre atividades realizadas por empresas privadas. Além de notícias de envolvimentos com ações sociais, encontram-se muitos releases de grandes empresas noticiando suas conquistas empresariais, contribuindo, dessa forma, para a construção de imaginários de prosperidade, sucesso e desenvolvimento econômico para Igrejinha. Percebe-se, nessas manchetes, a presença de elementos de construção de imagem (CHARTIER, 2002), os quais nos permitem melhor compreender como a imagem desempenha um papel fundamental da instrumentalização da força.

Diante disso, não se pode afirmar que a imagem da cidade explícita a partir das publicações do jornal é a mesma que seus habitantes têm, nem que essa é a real identidade do município. O que se nota é que pode haver uma intenção de imagem projetada a partir dos interesses dos políticos e empresários, pessoas que têm o poder e influência, bem como instrumentos para conseguir publicar suas ideias nos veículos de comunicação.

Ainda no grupo temático Geral, encontram-se algumas matérias polêmicas, que são denúncias da comunidade sobre a prefeitura, sobre o atendimento no hospital, postos de saúde, mas não são de número expressivo. Também há algumas notícias referentes a times de futebol, a cursos de aperfeiçoamento oferecidos por algumas instituições, entre outras que foram enquadradas na unidade "Demais Notícias".

Procurando relacionar a imagem construída pela imprensa local sobre a cidade com àquela difundida pela imprensa regional, consideramos importante analisar matérias do Jornal $\mathrm{NH}$ - que é um jornal de repercussão regional no Vale do Sinos e Paranhana e que tem um público leitor mais amplo e diversificado - referentes à Igrejinha, no ano de 2014. Através disso, pretendeu-se perceber nas publicações regionais, a respeito do município, a possibilidade de encontrar a mesma projeção de imagem e construção de identidades encontradas no jornal local.

$\mathrm{Na}$ busca pela palavra "Igrejinha", no site do jornal, foram encontradas 41 publicações sobre a cidade em 2014. Observa-se que a maioria das matérias, 26 , ou seja, mais de $50 \%$, são de notícias sobre assaltos, assassinatos, prisões por tráfico de drogas e também sobre acidentes, tragédias, no trânsito ou incêndios, por exemplo, mas com conotação de resolução, provavelmente oriundas da própria Polícia e do Corpo de Bombeiros da cidade de Igrejinha.

O segundo maior número de publicações sobre Igrejinha, nove matérias, são referentes à Oktoberfest, aos preparativos da AMIFEST. São textos maiores e com mais conteúdo, mas de caráter apenas informativo, visando a divulgar as atrações daquele ano. A maioria das matérias, algumas escritas e outras em vídeo, foram publicadas em setembro, período do ano bem próximo à data das 
festividades. Observa-se, com isso, que a imagem presente nas publicações do jornal local, não é a mesma encontrada no jornal regional, que apresenta caráter apenas informativo em seus textos, o que se contrapõe às representações veiculadas pela imprensa local.

\section{Considerações finais}

Pode-se afirmar que identidade não é a essência do sujeito, mas resultado de um complexo processo de escolhas, classificações e exclusões, dentro de um mundo de imaginários e representações, como também de domínio e manipulação das ideias e de imagens. Constatou-se, a partir da análise crítica sobre a imprensa local, que existe um olhar bastante positivo sobre Igrejinha, veiculado nas publicações do seu principal meio de comunicação, uma vez que, em sua maioria, as notícias exaltam seu potencial cultural, turístico, industrial e empresarial.

Conclui-se que a imagem de Igrejinha publicada nas páginas de seu principal jornal, é da cidade da Oktoberfest, "que ama, respira e vive essa festa o ano inteiro". Nas páginas da imprensa local, Igrejinha é a cidade da cultura alemã. Éa Igrejinha do desenvolvimento; com um número surpreendente de ruas asfaltadas; com obras acontecendo em toda a estrutura física da cidade; com a melhor educação da região; com empresas crescendo, expandindo seus negócios por todo o país, gerando empregos e, com isso, exaltando o nome da cidade.

Esses conceitos todos sobre a cidade estão contidos nas linhas de seu principal jornal, que tem funcionado como porta-voz do povo, com autorização de fala em nome da comunidade. Nesse sentido, a articulação entre o texto e o contexto foi fundamental para decifrar a representação do mundo social veiculada no jornal. Atenta-se para o fato de que essa projeção - e manipulação - da imagem de Igrejinha por parte daqueles que exercem certo poder e influência, no âmbito local, pode representar a defesa, muitas vezes, dos próprios interesses. Mas vale lembrar que também promove visibilidade para Igrejinha, trazendo, dessa forma, contribuições para o seu desenvolvimento.

\section{Referências}

ABREU, M. de A. Sobre a memória das cidades. Revista da Faculdade de Letras da Universidade do Porto, Porto, Portugal, v. XIV, p. 77-97, 1998.

BACZKO, B. A imaginação social. In: LEACH, E. et al. Anthropos-Homem. Lisboa, Imprensa Nacional/Casa da Moeda, 1985. p.296-332.

BOURDIEU, P. A economia das Trocas Lingüísticas: o que falar quer dizer. 2. ed. São Paulo: Editora da Universidade de São Paulo, 1998.

A produção da crença: contribuição para uma economia dos bens simbólicos. São Paulo: Zoouk, 2002.

O Poder Simbólico. 10. ed. Rio de Janeiro: Bertrand do Brasil, 2007.

CANDAU, J. Memória e identidade. Tradução Maria Leticia Ferreira. 1. ed. $1^{a}$ reimpr. São Paulo: Contexto, 2012.

CHARTIER, R. O Mundo Como Representação. In: CHARTIER, R. À Beira da Falésia: a história entre certezas e inquietudes. Porto Alegre: Ed. UFGRS, 1991. p. 81-100.

. À Beira da Falésia. A História entre certezas e inquietudes. Tradução de Patrícia Chittoni Ramos. Porto Alegre: Ed. UFGRS, 2002.

ENGELMANN, E. G. A saga dos alemães: do Hunsrück para Santa Maria do Mundo Novo. Igrejinha: E. G. Engelmann, 2004. v. 1.

GRÜNEWALD, R. de A. Os índios do Descobrimento: tradição e turismo. Rio de Janeiro: Contra Capa, 2003.

HALL, S. A centralidade da cultura: notas sobre as revoluções culturais do nosso tempo. Cultura, Mídia e Educação. Educação \& Realidade, Porto Alegre, v. 22, n. 2, p. 15-46, jul./dez. 1997.

\section{A Identidade Cultural na Pós-}

modernidade. Tradução de Tomaz Tadeu da Silva e 
Guacira Lopes Louro. 11. ed. Rio de Janeiro: DP\&A Editora, 2006.

JORNAL RS 115. Igrejinha, RS, 2014.

KAYSER, D. M. O processo de construção da marca "Oktoberfest Igrejinha": um estudo de caso. 2009. 85 f. Trabalho de Conclusão de Curso (Curso de Administração de Empresas) - Faculdades Integradas de Taquara, Taquara, 2009.

LEITÃO, J. A.; SANTOS, M. S. T. Imagem jornalística e representações sociais: a imagem dos Sertões. Intercom - RBCC, São Paulo, v. 35, n. 1, p. 133-155, jan./jun. 2012.

NEVES, L. de A. Literatura, memória e cidades: interseções. Scripta, Belo Horizonte, v. 7, n. 14, p. 137-145, $1^{\circ}$ sem. 2004.
PESAVENTO, S. J. Muito além do espaço: por uma história cultural do urbano. Estudos Históricos, Rio de Janeiro, v. 8, n. 16, p. 279-290, 1995.

SANTOS, M. A Natureza do Espaço: Técnica e Tempo, Razão e Emoção. São Paulo: Editora da USP, 2006.

SEYFERTH, G. A dimensão cultural da imigração. Revista Brasileira de Ciências Sociais, v. 26, n. 77, p. 47-62, 2011.

SPINK, M. J; P. O Conceito de Representação Social na Abordagem Psicossocial. Cad. Saúde Públ., Rio de Janeiro, v. 9, n. 3, p. 300-308, jul./set. 1993. 